・生物编目・

\title{
西藏墨脱不同海拔区乌鸟兽红外相机监测
}

\author{
吴建普 ${ }^{1}$ 罗 红 ${ }^{1,2 *}$ 朱雪林 ${ }^{1 *}$ 李炳章 $^{1}$ 刘务林 ${ }^{1}$ 次 平 ${ }^{1}$ \\ 1 (西藏自治区林业调查规划研究院，拉萨 850000) \\ 2 (中国林业科学研究院资源信息研究所, 北京 100091)
}

\section{Monitoring mammals and birds with camera traps at different altitudes of Medog, Tibet}

\author{
Jianpu $\mathrm{Wu}^{1}$, Hong Luo ${ }^{1,2^{*}}$, Xuelin $\mathrm{Zhu}^{1 *}$, Bingzhang $\mathrm{Li}^{1}$, Wulin Liu ${ }^{1}$, Ping $\mathrm{Ci}^{1}$ \\ 1 Forestry Inventory and Planning Institute of Tibet Autonomous Region, Lhasa 850000 \\ 2 Institute of Forest Resource Information Techniques, Chinese Academy of Forestry, Beijing 100091
}

西藏墨脱是中国生物多样性较丰富的区域之 一，鸟兽种类丰富，已记录有哺乳动物 70 种，鸟类 385 种 (郑作新等, 1983; 冯祚建等, 1986; 郭光普, 2004; 温立嘉等, 2014)。由于交通等条件的限制, 以 往对墨脱的鸟兽研究较少。随着2014年通往墨脱的 公路开通, 温立嘉等(2014)、廖锐等(2015)相继报道 了墨脱鸟兽相关的研究成果, 赵超等(2015)、梁丹等 (2014)报道了分布于墨脱的鸟类新记录, 如黑胸楔 嘴㭺鸟鹤(Sphenocichla humei)、猛隼(Falco severus)、 白胸翡翠(Halcyon smyrnensis)。Li等(2015)更是在墨 脱发现了猕猴属 (Macaca) 新种白规猕猴 (M. leucogenys)。

墨脱的地质环境复杂、气候条件特殊(中国科学 院植物研究所和中国科学院长春地理研究所, 1988; 郭光普, 2004), 在该区域内开展动物调查难度很 大。由于红外相机能捕获难以发现的物种, 已成为 调查鸟兽物种多样性、栖息地选择的常用手段(张履 冰等, 2014)。我们在墨脱不同海拔的样区布设多台 红外相机, 旨在监测不同海拔和区域的鸟兽种类及 其变化, 以丰富墨脱不同区域和海拔鸟兽的分布记 录及其生物多样性研究。

\section{1 研究地点和方法}

\section{1 监测区概况}

墨脱县位于西藏自治区东南部，地处雅鲁藏布
江下游、喜马拉雅山东端南坡。地理位置为 $93^{\circ} 46^{\prime}-$ $96^{\circ} 05^{\prime} \mathrm{E}, 27^{\circ} 33^{\prime}-29^{\circ} 56^{\prime} \mathrm{N}$, 面积约 $31,080.82 \mathrm{~km}^{2}$ 。本 次监测区集中在格当区 (放置红外相机的地点平均 海拔 $2,315 \mathrm{~m})$ 、西贡河区 $(1,590 \mathrm{~m})$ 、德阳沟区 $(1,294$ m) 3 个样区 (最高海拔 $2,452 \mathrm{~m}$, 最低海拔 $850 \mathrm{~m}$ ) (图1)。

监测区域属于亚热带湿润气候区(廖锐等, 2015), 海拔800-2,500 m, 植被属于中山亚热带常 绿和常绿与落叶阔叶混交林, 境内亚热带常绿和常 绿落叶阔叶混交林与其他地区一样, 建群树种以壳 斗科、樟科、山茶科、木兰科、五加科等占优势, 混 有落叶阔叶树分布。一般在海拔 $1,800 \mathrm{~m}$ 以下为常绿 阔叶林, 海拔 $1,800 \mathrm{~m}$ 以上为常绿与落叶阔叶混交 林(中国科学院植物研究所和中国科学院长春地理 研究所, 1988)。

\section{2 监测方法}

2013年10月16-25日，在墨脱格当区的常绿落 叶阔叶混交林、落叶阔叶林、寒温性针叶林、暖性 针叶林, 德阳沟区的常绿阔叶林, 以及西贡河区的 常绿阔叶林中, 选择远离人为干扰的鸟兽适宜生 境, 共放置32台红外相机。将红外相机安装在树干 距地面的20-60 $\mathrm{cm}$ 处, 并面朝目标拍摄区域。样区 内相邻相机间的最小间隔距离为 $188 \mathrm{~m}$, 最大间隔 距离为 $9,122 \mathrm{~m}$ 。红外相机未进行伪装和遮蔽, $24 \mathrm{~h}$

收稿日期: 2015-09-15; 接受日期: 2016-01-24

基金项目: 西藏自治区第二次陆生野生动物资源调查项目

* 共同通讯作者 Co-authors for correspondence. E-mail: luohong841014@sina.com; zxllsxz@163.com 


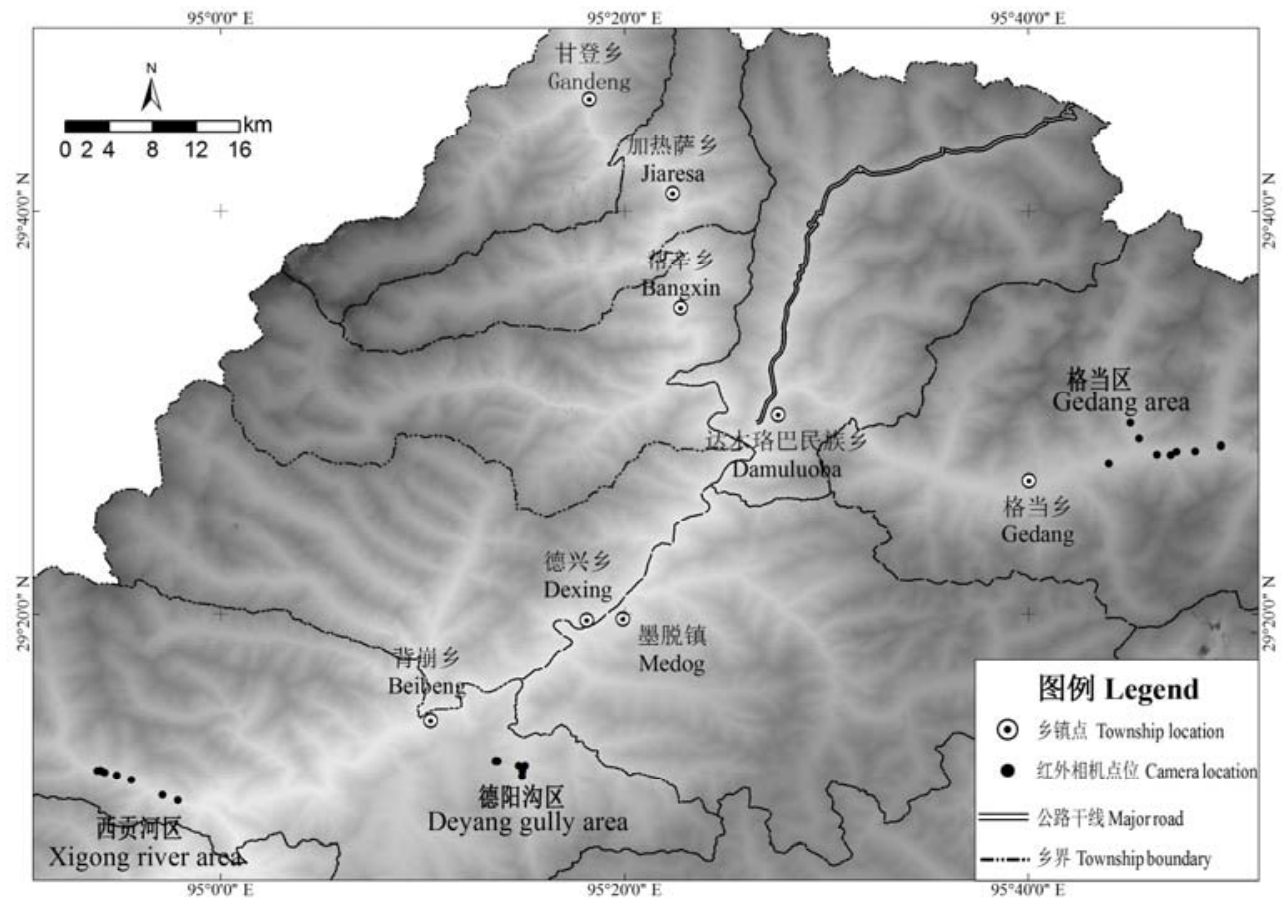

图1 西藏墨脱红外相机布设位点示意图

Fig. 1 Sketch map of infrared camera positions in Medog, Tibet

不间断工作，通过被动式红外线移动探测器来触发 相机拍摄。红外相机每次触发后拍摄 3 张照片和 1 段 $15 \mathrm{~s}$ 的视频。为了保持一定的拍摄时间, 将红外相机 设置为中度敏感水平。未采用食物或引诱剂吸引动 物。研究期间, 每个相机中放置 16 G的SD存储卡和 12节AA电池，在相机收回之前未更换电池也未检 查相机。于2014年4月16-25日，成功回收23台，1台 无效, 其余22台均记录到鸟兽。另外 9 台红外相机丢 失。监测时间约为 $180 \mathrm{~d}$ 。

\section{3 数据记录和处理分析}

记录每台相机安放位置(视为 1 个样地，样地号 为红外相机编号)的经纬度、海拔、植被类型以及安 放和取回的时间。每次连续拍摄的 3 张照片和 1 段视 频中出现的同种动物, 频次计为 1 次, 并统计出现 率(trapping rate)(温立嘉等, 2014)。动物分类采用 Smith等(2009)、郑光美(2011)和蒋志刚等(2015)的分 类系统。通过记录各红外相机点位的海拔, 统计各 样区内放置红外相机海拔的算术平均值。

同一物种的连续照片以间隔 $30 \mathrm{~min}$ 作为 1 次独立 捕获, 记录成 1 张独立照片, 建立Excel数据库, 记录 各样地不同物种出现的照片总数和独立照片数。
将各物种出现的独立照片数与所拍摄动物独 立照片总数的百分比作为各物种的相对丰富度 (relative abundance index, $R A I)$ 。计算公式如下(董潭 成等, 2014):

$$
R A I=\frac{A_{\mathrm{i}}}{N} \times 100
$$

式中, $A_{\mathrm{i}}$ 为第 $\mathrm{i}$ 类 $(\mathrm{i}=1, \ldots 19 \ldots, 37)$ 动物出现的独立 照片数; $N$ 为所拍摄动物独立照片总数。

参照董潭成等(2014)的相机拍摄率计算方法, 将样地的动物独立照片数与该样地相机工作日的 百分比作为各样地的相机拍摄率 (capture frequencies index, $C F I)$ 。计算公式如下:

$$
C F I=\frac{N_{\mathrm{j}}}{T_{\mathrm{j}}}
$$

式中, $N_{\mathrm{j}}$ 指第 $\mathrm{j}$ 个 $(\mathrm{j}=1, \ldots 11 \ldots, 22)$ 样地动物的独立 照片数; $T_{\mathrm{j}}$ 指第 $\mathrm{j}$ 个样地的相机工作日。各样区的相 机拍摄率取其样地算术平均值。

\section{2 结果}

\section{1 整个监测区物种及其相对丰富度}

本次记录到鸟兽共 18 科 37 种，其中鸟类 7 科 18 
种，兽类11科19种(附录1)。

出现率最高的物种为白颊猕猴, 为 $23.20 \%$, 林 鹿(Muntiacus feae)、紫啸冻(Myophonus caeruleus)、 野猪 (Sus scrofa) 、赤腹松鼠 (Callosciurus erythraeus)、喜马拉雅镾羚(Capricornis thar)、黄喉 貂(Martes flavigula)、黑熊(Ursus thibetanus)、豹猫 (Prionailurus bengalensis)、黑酠(Lophura leucomelanos)、金猫(Pardofelis temminckii)等物种的出现率 也较高(附录1)。此外, 还拍摄到戴帽叶猴(Trachypithecus shortridgei)、小熊猫(Ailurus fulgens)、不丹 羚牛(Budorcas whitei)、云猫(Pardofelis marmorata)、 云豹(Neofelis nebulosa)、果子狸(Paguma larvata) 等 珍稀濒危物种 (附录1)。

物种相对丰富度最高的为林鹿(16.30\%), 其后 依次为紫啸鸫 $(15.08 \%)$ 、赤腹松鼠、白颊猕猴、野 猪、黄喉貂、喜马拉雅镾羚、豹猫等(附录1)。

\section{2 不同样区物种及其相对丰富度}

按样区分，格当区共拍摄到鸟兽17科24种，其 中鸟类 7 科 11 种, 兽类 10 科 13 种; 德阳沟区共拍摄 到鸟兽 15 科 27 种，其中鸟类 6 科 12 种，兽类 9 科 15 种; 西贡河区共拍摄到鸟兽 10 科 18 种，其中鸟类 3 科 8 种, 兽类 7 科 10 种 (附录 1 )。物种数量以德阳沟区最 高, 格当区次之, 西贡河区最低。

按区域分, 格当区拍摄频次 $\geqslant 10$ 的物种依次为 白㚘猕猴、林鹿、野猪、赤腹松鼠、喜马拉雅鬌羚、 黑熊、黑闲、金猫、豹猫和环颈山麅鸪(Arborophila torqueola); 德阳沟区拍摄频次 $\geqslant 10$ 的物种依次为 紫啸鸫、白㚘猕猴、黄喉貂和豹猫。西贡河区拍摄 频次 $\geqslant 10$ 的物种为赤鹿(Muntiacus vaginalis)和黄喉 貂(附录1)。

格当区物种相对丰富度最高的为林鹿 $(25.73 \%)$, 其后依次为赤腹松鼠、白颊猕猴、野猪、 喜马拉雅镾羚、黑熊等。德阳沟区物种相对丰富度 最高的为紫啸鸫 $(46.08 \%)$, 其后依次为黄喉貂、豹 猫、喜马拉雅镾羚、白颊猕猴等。西贡河区物种相 对丰富度最高的为赤鹿 $(25.00 \%)$, 其后依次为黄喉 貂、紫啸冻、环颈山䳸鸪、㥪(Cuon alpinus)、喜马 拉雅鬛羚、巨松鼠(Ratufa bicolor)、豹猫等(附录1)。

样区拍摄率以格当区 $(0.29)$ 最高, 德阳沟区次 之, 西贡河区最低 $(0.10)$ 。样地拍摄率以格当区9样 地(0.55)最高, 德阳沟的27样地(0.01)最低(附录2)。

\section{3 讨论}

\section{1 物种多样性}

温立嘉等(2014)在墨脱雅鲁藏布江海拔 1,200 $\mathrm{m}$ 附近架设 12 台红外相机, 记录到鸟兽 16 科 32 种, 结合本次研究, 两次共记录22科 54 种。本次更是记 录到白颊猕猴、戴帽叶猴、林鹿、不丹羚牛、小熊 猫、㥪、鹰雕(Spizaetus nipalensis)等, 证实了墨脱 县拥有丰富的生物多样性, 且白㚘猕猴和林鹿的拍 摄频次和物种相对丰富度很高。拍摄到的白颊猕猴 分布区在该物种新种描述的分布区内 ( $\mathrm{Li}$ et al, 2015)。戴帽叶猴分布于云南西北部和藏东南(盛和 林，2005; Smith等，2009), 但在藏东南的分布以前 少有研究证明，本次在德阳沟区拍摄到，不仅表明 德阳沟区是该物种重要的分布区，同时证实了其在 藏东南的分布。墨脱虽有林鹿和赤鹿分布，但林鹿 $(16.30 \%)$ 的物种丰富度明显高于赤鹿 $(2.44 \%)$ 。喜马 拉雅镾羚、黑㭤、金猫、豹猫、黄喉貂、紫啸冻等 不仅在 3 个样区都记录到, 也在墨脱雅鲁藏布江海 拔1,200 m附近被记录到(温立嘉等, 2014), 说明这 些物种在墨脱分布较广。

\section{2 物种海拔区分布变化}

本次记录到的白颊狝猴、戴帽叶猴、小熊猫、 不丹羚牛、林鹿等在墨脱雅鲁藏布江海拔 $1,200 \mathrm{~m}$ 附 近未曾被记录到(温立嘉等, 2014)。戴帽叶猴、小熊 猫、不丹羚牛、鹰雕等虽然被本次记录, 但也仅在 1 台相机上记录 1 次或 2 次。白颊猕猴、林鹿、赤腹松 鼠和野猪在平均海拔 $2,315 \mathrm{~m}$ 的格当区拍摄较多, 分别占该物种总拍摄频次的 $90.16 \% 、 82.45 \%$ 、 $90.24 \%$ 和 $100 \%$ ，白规猕猴在格当区分布广泛，在该 区9台相机中有 8 台记录到, 野猪仅在格当区被记 录, 格当区的拍摄率和海拔在样区中最高。而紫啸 鸫在平均海拔 1,294 $\mathrm{m}$ 的德阳沟区拍摄频次最多, 占该物种总拍摄频次的 $91.34 \%$, 物种丰富度也占到 了 46.08\%。林鹿在格当区和德阳沟区均有记录, 而 赤鹿仅在1,590 m的西贡河区被记录。在墨脱不仅鸟 兽种类在海拔区不同, 拍摄率和物种丰富度在各海 拔区也存在差异。

致谢: 感谢墨脱县林业局和影像生物调查所的徐 健、郭亮老师在野外工作中提供帮助，感谢中国科 学院动物研究所蒋志刚研究员和中国科学院昆明 动物研究所蒋学龙研究员在论文及物种整理上提 
供宝贵建议，感谢黄乘明研究员、胡慧建研究员、 韩联宪教授、宋大昭老师帮助鉴定物种。

\section{参考文献}

Dong TC, Chu HJ, Wu HP, Wang Y, Ge Y, Bu L (2014) Monitoring birds and mammals through camera traps in Mount Kalamaili Ungulate Nature Reserve, Xinjiang. Biodiversity Science, 22, 804-807. (in Chinese) [董潭成, 初红军, 吴洪潘, 王渊, 葛炎, 布兰 (2014) 卡拉麦里山 有蹄类自然保护区乌兽的红外相机监测. 生物多样性, 22, 804-807.]

Feng ZJ, Cai GQ, Zheng CL (1986) The Mammals of Xizang. Science Press, Beijing. (in Chinese) [冯祚建, 蔡桂全, 郑 昌琳 (1986) 西藏哺乳类. 科学出版社, 北京.]

Guo GP (2004) Study on the Relationships Between Local People and Wildlife in Medog, Tibet, China. PhD dissertation, East China Normal University, Shanghai. (in Chinese with English abstract) [郭光普 (2004) 西藏墨脱 县野生动物和当地居民之间的关系研究. 博士学位论文, 华东师范大学, 上海.]

Institute of Botany, The Chinese Academy of Sciences, Changchun Institute of Geography, Chinese Academy of Sciences (1988) Tibet Vegetation. Science Press, Beijing. (in Chinese) [中国科学院植物研究所, 中国科学院长春地 理研究所 (1988) 西藏植被. 科学出版社, 北京.]

Jiang ZG, Ma Y, Wu Y, Wang YX, Feng ZJ, Zhou KY, Liu SY, Luo ZH, Li CW (2015) China's mammalian diversity. Biodiversity Science, 23, 351-364. (in Chinese with English abstract) [蒋志刚, 马勇, 吴毅, 王应祥, 冯祚建, 周开亚, 刘少英, 罗振华, 李春旺 (2015) 中国哺乳动物多样性. 生物多样性, 23, 351-364.]

Li C, Zhao C, Fan PF (2015) White-cheeked macaque (Macaca leucogenys): a new macaque species from Modog, southeastern Tibet. American Journal of Primatology, 77, 753-766.

Liang D, Li BZ, Liu WL, Zhang Q (2014) Falco severusd and Halcyon smyrnensis discovered in Medog County, Tibet. Chinese Journal of Zoology, 49, 463. (in Chinese) [梁丹, 李 炳章, 刘务林, 张庆 (2014) 西藏墨脱发现猛隼和白胸翡 翠. 动物学杂志, 49, 463.]

Liao R, Guo GP, Liu Y, Jin W, Liu SY (2015) Biodiversity of small mammals in Medog County, Tibet of China. Journal of Sichuan Forestry Science and Technology, 36, 6-10. (in Chinese with English abstract) [廖锐, 郭光普, 刘阳, 靳伟, 刘少英 (2015) 西藏墨脱县小型兽类多样性研究. 四川 林业科技, 36, 6-10.]

Sheng HL (2005) Atlas of Reptilia of China. Henan Science and Technology Press, Zhengzhou. (in Chinese) [盛和林 (2005) 中国哺乳动物图鉴. 河南科学技术出版社, 郑州.]

Smith A, Xie Y, Hoffmann RS, Lunde D, MacKinnon J, Wilson DE, Wozencraft WC, Gemma F (2009) A Guide to the Mammals of China. Hunan Education Publishing House, Changsha. (in Chinese) [Smith A, 解炎, Hoffmann RS, Lunde D, MacKinnon J, Wilson DE, Wozencraft WC, Gemma F (2009) 中国兽类野外手册. 湖南教育出版社, 长沙.]

Wen LJ, Shi K, Huang J, Song Y, Guo YM (2014) Preliminary analysis of mammal and bird diversity monitored with camera traps in Medog, Tibet. Biodiversity Science, 22, 798-799. (in Chinese) [温立嘉, 时坤, 黄建, 宋阳, 郭玉 民 (2014) 西藏墨脱鸟兽红外相机监测初报. 生物多样 性, 22, 798-799.]

Zhang LB, Cui SP, Huang YJ, Chen DQ, Qiao HJ, Li CW, Jiang ZG (2014) Infrared camera traps in wildlife research and monitoring in China: issues and insights. Biodiversity Science, 22, 696-703. (in Chinese with English abstract) [张 履冰, 崔绍朋, 黄元骏, 陈代强, 乔慧捷, 李春旺, 蒋志 刚 (2014) 红外相机技术在我国野生动物监测中的应用: 问题与限制. 生物多样性, 22, 696-703.]

Zhao C, Fan PF, Xiao W (2015) Discovery of Sikkim Wedge-billed Babbler (Sphenocichla humei) in Medog, Tibet, China. Chinese Journal of Zoology, 50, 141-144. (in Chinese with English abstract) [赵超, 范朋飞, 肖文 (2015) 西藏墨脱发现黑胸楔嘴缭鹤. 动物学杂志, 50, 141-144.]

Zheng ZX, Li DH, Wang ZX, Wang ZY, Jiang ZH, Lu TC (1983) The Avifauna of Xizang. Science Press, Beijing. (in Chinese) [郑作新, 李德浩, 王祖祥, 王子玉, 江智华, 卢 汰春 (1983) 西藏鸟类志. 科学出版社, 北京.]

Zheng GM (2011) A Checklist on the Classification and Distribution of the Birds of China, 2nd edn. Science Press, Beijing. (in Chinese) [郑光美 (2011) 中国鸟类分类与分 布名录, 第2版. 科学出版社, 北京.]

(责任编辑：间文杰)

\section{附录 Supplementary Material}

\section{附录1 西藏墨脱3个区域红外相机记录到的鸟兽种类}

Appendix 1 Mammals and birds recorded by infrared cameras in three areas of Medog, Tibet http://www.biodiversity-science.net/fileup/PDF/2015106-1.pdf

\section{附录2 西藏墨脱3个区域红外相机监测及拍摄率}

Appendix 2 Camera trapping effort and capture frequencies index in three areas of Medog, Tibet http://www.biodiversity-science.net/fileup/PDF/2015106-2.pdf 
吴建普, 罗红, 朱雪林, 李炳章, 刘务林, 次平. 西藏墨脱不同海拔区鸟兽红外相机监测. 生物多样性, 2016, 24 (3): 351-354. http://www.biodiversity-science.net/CN/10.17520/biods.2015106

附录 1 西藏墨脱 3 个区域红外相机记录到的鸟兽种类

Appendix 1 Mammals and birds recorded by infrared cameras in three areas of Medog, Tibet

\begin{tabular}{|c|c|c|c|c|c|c|c|c|c|c|c|c|c|c|c|c|c|}
\hline 物种 Species & & $\begin{array}{l}\text { 拍摄 } \\
\text { Frequ }\end{array}$ & $\begin{array}{l}\text { 频次 } \\
\text { lency of ca }\end{array}$ & apture & & $\begin{array}{l}\text { 出现莘 } \\
\text { Trappi }\end{array}$ & ng rate (\% & & & $\begin{array}{l}\text { 独立! } \\
\text { Indep }\end{array}$ & $\begin{array}{l}\text { 照片数 } \\
\text { pendent ph }\end{array}$ & hotos & & $\begin{array}{l}\text { 相对丰 } \\
\text { Relat }\end{array}$ & $\begin{array}{l}\text { 丰富度 } \\
\text { tive abun }\end{array}$ & adance in & ndex (\%) \\
\hline & & $\begin{array}{l}\text { Ge- } \\
\text { dang }\end{array}$ & $\begin{array}{l}\text { Deyang } \\
\text { gully }\end{array}$ & $\begin{array}{c}\text { Xigong } \\
\text { river }\end{array}$ & Total & $\begin{array}{l}\text { Ge- } \\
\text { dang }\end{array}$ & $\begin{array}{l}\text { Deyang } \\
\text { gully }\end{array}$ & $\begin{array}{l}\text { Xigong } \\
\text { river }\end{array}$ & Total & $\begin{array}{l}\text { Ge- } \\
\text { dang }\end{array}$ & $\begin{array}{l}\text { Deyang } \\
\text { gully }\end{array}$ & $\begin{array}{c}\text { Xigong } \\
\text { river }\end{array}$ & Total & $\begin{array}{l}\text { Ge- } \\
\text { dang }\end{array}$ & $\begin{array}{l}\text { Deyang } \\
\text { gully }\end{array}$ & $\begin{array}{c}\text { Xigong } \\
\text { river }\end{array}$ & Total \\
\hline 兽类 Mammals & & & & & & & & & & & & & & & & & \\
\hline 猴科 Cercopithecidae & 白颊猕猴 Macaca leucogenys & 229 & 25 & 0 & 254 & 30.86 & 9.43 & 0.00 & 23.20 & 66 & 7 & 0 & 73 & 14.77 & 3.23 & 0.00 & 9.92 \\
\hline & 戴帽叶猴 Trachypithecus shortridgei & 0 & 2 & 0 & 2 & 0.00 & 0.75 & 0.00 & 0.18 & 0 & 2 & 0 & 2 & 0.00 & 0.92 & 0.00 & 0.27 \\
\hline 猫科 Felidae & 豹猫 Prionailurus bengalensis & 12 & 21 & 3 & 36 & 1.63 & 7.92 & 3.41 & 3.29 & 13 & 18 & 3 & 34 & 2.92 & 8.29 & 4.16 & 4.62 \\
\hline & 云猫 Pardofelis marmorata & 0 & 0 & 1 & 1 & 0.00 & 0.00 & 1.14 & 0.09 & 0 & 0 & 1 & 1 & 0.00 & 0.00 & 1.39 & 0.13 \\
\hline & 云豹 Neofelis nebulosa & 0 & 1 & 0 & 1 & 0.00 & 0.38 & 0.00 & 0.09 & 0 & 1 & 0 & 1 & 0.00 & 0.47 & 0.00 & 0.13 \\
\hline & 金猫 Pardofelis temminckii & 15 & 4 & 1 & 20 & 2.02 & 1.51 & 1.14 & 1.83 & 14 & 2 & 1 & 17 & 3.13 & 0.92 & 1.39 & 2.31 \\
\hline 熊科 Ursidae & 黑熊 Ursus thibetanus & 38 & 4 & 0 & 42 & 5.13 & 1.51 & 0.00 & 3.84 & 24 & 4 & 0 & 28 & 5.37 & 1.85 & 0.00 & 3.80 \\
\hline 鼣科 Mustelidae & 黄喉貂 Martes flavigula & 9 & 25 & 16 & 50 & 1.22 & 9.43 & 18.18 & 4.57 & 8 & 25 & 16 & 49 & 1.79 & 11.53 & 22.22 & 6.65 \\
\hline 小熊猫科 Ailuridae & 小熊猫 Ailurus fulgens & 1 & 0 & 0 & 1 & 0.13 & 0.00 & 0.00 & 0.09 & 2 & 0 & 0 & 2 & 0.45 & 0.00 & 0.00 & 0.27 \\
\hline 犬科 Canidae & 豹 Cuon alpinus & 3 & 2 & 7 & 12 & 0.40 & 0.75 & 7.95 & 1.10 & 3 & 2 & 4 & 9 & 0.67 & 0.92 & 5.56 & 1.22 \\
\hline 灵猫科 Viverridae & 果子狸 Paguma larvata & 0 & 5 & 1 & 6 & 0.00 & 1.89 & 1.14 & 0.55 & 0 & 5 & 1 & 6 & 0.00 & 2.30 & 1.38 & 0.82 \\
\hline 猪科 Suidae & 野猪 Sus scrofa & 101 & 0 & 0 & 101 & 13.62 & 0.00 & 0.00 & 9.22 & 52 & 0 & 0 & 52 & 11.63 & 0.00 & 0.00 & 7.07 \\
\hline 鹿科 Cervidae & 赤鹿 Muntiacus vaginalis & 0 & 0 & 25 & 25 & 0.00 & 0.00 & 28.41 & 2.28 & 0 & 0 & 18 & 18 & 0.00 & 0.00 & 25.00 & 2.44 \\
\hline & 林鹿 Muntiacus feae & 155 & 8 & 0 & 163 & 20.89 & 3.02 & 0.00 & 14.88 & 115 & 5 & 0 & 120 & 25.73 & 2.30 & 0.00 & 16.30 \\
\hline 牛科 Bovidae & 不丹羚牛 Budorcas whitei & 0 & 2 & 0 & 2 & 0.00 & 0.75 & 0.00 & 0.18 & 0 & 2 & 0 & 2 & 0.00 & 0.93 & 0.00 & 0.27 \\
\hline & 喜马拉雅鬛羚 Capricornis thar & 44 & 9 & 4 & 57 & 5.93 & 3.40 & 4.54 & 5.20 & 34 & 8 & 3 & 45 & 7.61 & 3.69 & 4.17 & 6.11 \\
\hline & 喜马拉雅斑羚 Naemorhedus goral & 9 & 1 & 0 & 10 & 1.22 & 0.38 & 0.00 & 0.91 & 4 & 1 & 0 & 5 & 0.89 & 0.47 & 0.00 & 0.68 \\
\hline 松鼠科 Sciuridae & 赤腹松鼠 Callosciurus erythraeus & 74 & 7 & 1 & 82 & 9.97 & 2.64 & 1.14 & 7.49 & 70 & 6 & 1 & 77 & 15.66 & 2.76 & 1.39 & 10.46 \\
\hline & 巨松鼠 Ratufa bicolor & 8 & 5 & 5 & 18 & 1.08 & 1.89 & 5.68 & 1.64 & 6 & 4 & 3 & 13 & 1.34 & 1.84 & 4.17 & 1.77 \\
\hline 鸟类 Birds & & & & & & & & & & & & & & & & & \\
\hline 鹰科 Accipitridae & 鹰雕 Spizaetus nipalensis & 2 & 0 & 0 & 2 & 0.27 & 0.00 & 0.00 & 0.18 & 1 & 0 & 0 & 1 & 0.22 & 0.00 & 0.00 & 0.14 \\
\hline 雉科 Phasianidae & 黑鸿 Lophura leucomelanos & 19 & 4 & 5 & 28 & 2.56 & 1.51 & 5.68 & 2.56 & 13 & 4 & 3 & 20 & 2.91 & 1.84 & 4.17 & 2.72 \\
\hline & 环颈山府鸪 Arborophila torqueola & 10 & 0 & 5 & 15 & 1.35 & 0.00 & 5.68 & 1.37 & 8 & 0 & 5 & 13 & 1.79 & 0.00 & 6.94 & 1.77 \\
\hline
\end{tabular}




\begin{tabular}{|c|c|c|c|c|c|c|c|c|c|c|c|c|c|c|c|c|c|c|}
\hline \multirow{3}{*}{\multicolumn{2}{|c|}{ 物种 Species }} & & \multicolumn{4}{|c|}{$\begin{array}{l}\text { 拍摄频次 } \\
\text { Frequency of capture }\end{array}$} & \multicolumn{4}{|c|}{$\begin{array}{l}\text { 出现率 } \\
\text { Trapping rate (\%) } \\
\end{array}$} & \multicolumn{4}{|c|}{$\begin{array}{l}\text { 独立照片数 } \\
\text { Independent photos }\end{array}$} & \multicolumn{4}{|c|}{$\begin{array}{l}\text { 相对丰富度 } \\
\text { Relative abundance index (\%) }\end{array}$} \\
\hline & & & 格当 & $\begin{array}{l}\text { 德阳沟 } \\
\end{array}$ & $\begin{array}{l}\text { 西贡河 } \\
\end{array}$ & 总计 & 格当 & 德阳沟 & 西贡河 & 总计 & 格当 & 德阳沟 & $\begin{array}{l}\text { 西贡河 } \\
\end{array}$ & 总计 & 格当 & 德阳沟 & 西贡河 & 总计 \\
\hline & & & $\begin{array}{l}\text { Ge- } \\
\text { dang }\end{array}$ & $\begin{array}{l}\text { Deyang } \\
\text { gully }\end{array}$ & $\begin{array}{c}\text { Xigong } \\
\text { river }\end{array}$ & Total & $\begin{array}{l}\text { Ge- } \\
\text { dang }\end{array}$ & $\begin{array}{l}\text { Deyang } \\
\text { gully }\end{array}$ & $\begin{array}{l}\text { Xigong } \\
\text { river }\end{array}$ & Total & $\begin{array}{l}\text { Ge- } \\
\text { dang }\end{array}$ & $\begin{array}{l}\text { Deyang } \\
\text { gully }\end{array}$ & $\begin{array}{c}\text { Xigong } \\
\text { river }\end{array}$ & Total & $\begin{array}{l}\text { Ge- } \\
\text { dang }\end{array}$ & $\begin{array}{l}\text { Deyang } \\
\text { gully }\end{array}$ & $\begin{array}{c}\text { Xigong } \\
\text { river }\end{array}$ & Total \\
\hline 鸦科 & Corvidae & 黄嘴蓝鹊 Urocissa flavirostris & 2 & 1 & 0 & 3 & 0.27 & 0.38 & 0.00 & 0.27 & 2 & 1 & 0 & 3 & 0.45 & 0.46 & 0.00 & 0.41 \\
\hline \multirow[t]{4}{*}{ 画眉 } & 科 Timaliidae & 白冠噪眉 Garrulax leucolophus & 0 & 1 & 2 & 3 & 0.00 & 0.38 & 2.27 & 0.27 & 0 & 1 & 2 & 3 & 0.00 & 0.46 & 2.78 & 0.41 \\
\hline & & 纯色噪扸 Garrulax subunicolor & 0 & 2 & 2 & 4 & 0.00 & 0.75 & 2.27 & 0.37 & 0 & 1 & 2 & 3 & 0.00 & 0.46 & 2.78 & 0.41 \\
\hline & & 橙翅噪鹛 Garrulax elliotii & 1 & 1 & 1 & 3 & 0.13 & 0.38 & 1.14 & 0.27 & 1 & 0 & 1 & 2 & 0.22 & 0.00 & 1.39 & 0.27 \\
\hline & & 黑顶噪煟 Garrulax affinis & 2 & 5 & 0 & 7 & 0.27 & 1.89 & 0.00 & 0.64 & 2 & 5 & 0 & 7 & 0.45 & 2.30 & 0.00 & 0.95 \\
\hline \multirow[t]{7}{*}{ 冻科 } & Turdidae & 紫啸冻 Myophonus caeruleus & 4 & 116 & 7 & 127 & 0.54 & 43.77 & 7.95 & 11.60 & 5 & 100 & 6 & 111 & 1.12 & 46.08 & 8.33 & 15.08 \\
\hline & & 斑背燕尾 Enicurus maculates & 0 & 1 & 0 & 1 & 0.00 & 0.38 & 0.00 & 0.09 & 0 & 1 & 0 & 1 & 0.00 & 0.46 & 0.00 & 0.14 \\
\hline & & 灰背燕尾 Enicurus schistaceus & 0 & 4 & 0 & 4 & 0.00 & 1.51 & 0.00 & 0.37 & 0 & 4 & 0 & 4 & 0.00 & 1.84 & 0.00 & 0.54 \\
\hline & & 白颈冻 Turdus albocinctus & 1 & 0 & 0 & 1 & 0.13 & 0.00 & 0.00 & 0.09 & 1 & 0 & 0 & 1 & 0.22 & 0.00 & 0.00 & 0.14 \\
\hline & & 橙头地冻 Zoothera citrina & 0 & 0 & 1 & 1 & 0.00 & 0.00 & 1.14 & 0.09 & 0 & 0 & 1 & 1 & 0.00 & 0.00 & 1.39 & 0.14 \\
\hline & & 光背地冻 Zoothera mollissima & 0 & 0 & 1 & 1 & 0.00 & 0.00 & 1.14 & 0.09 & 0 & 0 & 1 & 1 & 0.00 & 0.00 & 1.39 & 0.14 \\
\hline & & 白顶溪鸲 Chaimarrornis leucocephalus & 0 & 5 & 0 & 5 & 0.00 & 1.89 & 0.00 & 0.46 & 0 & 5 & 0 & 5 & 0.00 & 2.30 & 0.00 & 0.68 \\
\hline 莺科 & Sylviidae & 褐柳莺 Phylloscopus fuscatus & 1 & 1 & 0 & 2 & 0.13 & 0.38 & 0.00 & 0.18 & 1 & 1 & 0 & 2 & 0.22 & 0.46 & 0.00 & 0.27 \\
\hline \multirow[t]{2}{*}{ 鹟科 } & Muscicapidae & 方尾䳜 Culicicapa ceylonensis & 1 & 0 & 0 & 1 & 0.13 & 0.00 & 0.00 & 0.09 & 1 & 0 & 0 & 1 & 0.22 & 0.00 & 0.00 & 0.14 \\
\hline & & 棕腹蓝仙鹟 Niltava vivida & 1 & 3 & 0 & 4 & 0.13 & 1.13 & 0.00 & 0.37 & 1 & 2 & 0 & 3 & 0.22 & 0.92 & 0.00 & 0.41 \\
\hline 小计 & Total & & 742 & 265 & 88 & 1,095 & 100.00 & 100.00 & 100.00 & 100.00 & 447 & 217 & 72 & 736 & 100.00 & 100.00 & 100.00 & 100.00 \\
\hline
\end{tabular}


吴建普, 罗红, 朱雪林, 李炳章, 刘务林, 次平. 西藏墨脱不同海拔区鸟兽红外相机监测. 生物多样性, 2016, 24 (3): 351-354. http://www.biodiversity-science.net/CN/10.17520/biods.2015106

附录2 西藏墨脱3个区域红外相机监测及拍摄率

Appendix 2 Camera trapping effort and capture frequencies index in three areas of Medog, Tibet

\begin{tabular}{|c|c|c|c|c|c|c|c|c|c|c|c|c|c|c|c|c|c|c|c|c|c|c|}
\hline & \multicolumn{9}{|c|}{ 格当 Gedang } & \multicolumn{8}{|c|}{ 德阳沟 Deyang gully } & \multicolumn{5}{|c|}{ 西贡河 Xigong river } \\
\hline & 2 & 3 & 4 & 5 & 6 & 9 & 10 & 31 & 32 & 11 & 12 & 15 & 17 & 18 & 19 & 20 & 27 & 22 & 23 & 24 & 25 & 26 \\
\hline 相机工作日 Camera trapping days & 142 & 184 & 155 & 185 & 185 & 185 & 183 & 153 & 152 & 150 & 173 & 144 & 172 & 171 & 171 & 165 & 171 & 157 & 62 & 129 & 158 & 151 \\
\hline 独立照片数 Independent photos & 51 & 34 & 28 & 73 & 65 & 101 & 32 & 38 & 25 & 110 & 31 & 13 & 11 & 12 & 21 & 17 & 2 & 17 & 2 & 12 & 20 & 21 \\
\hline 拍摄率 Capture frequencies index & 0.36 & 0.18 & 0.18 & 0.39 & 0.35 & 0.55 & 0.17 & 0.25 & 0.16 & 0.73 & 0.18 & 0.09 & 0.06 & 0.07 & 0.12 & 0.11 & 0.01 & 0.11 & 0.03 & 0.09 & 0.13 & 0.14 \\
\hline & & & & & 0.29 & & & & & & & & & & & & & & & 0.10 & & \\
\hline
\end{tabular}

